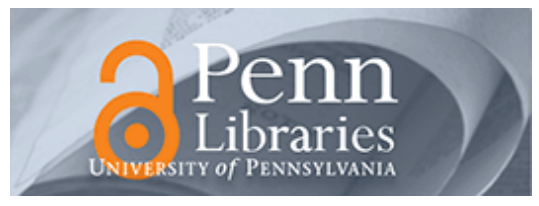

University of Pennsylvania

ScholarlyCommons

Operations, Information and Decisions Papers

Wharton Faculty Research

$12-2008$

\title{
A Theoretical Framework for Goal-Based Choice and For Prescriptive Analysis
}

Kurt A. Carlson

Chris Janiszewski

Ralph L. Keeney

David H. Krantz

Howard Kunreuther

University of Pennsylvania

See next page for additional authors

Follow this and additional works at: https://repository.upenn.edu/oid_papers

Part of the Human Ecology Commons, Organizational Behavior and Theory Commons, Other Social and Behavioral Sciences Commons, and the Other Sociology Commons

\section{Recommended Citation}

Carlson, K. A., Janiszewski, C., Keeney, R. L., Krantz, D. H., Kunreuther, H., Luce, M. F., Russo, J. E., Osselaer, S., \& Winterfeldt, D. V. (2008). A Theoretical Framework for Goal-Based Choice and For Prescriptive Analysis. Marketing Letters, 19 (3), 241-254. http://dx.doi.org/10.1007/s11002-008-9043-4

This paper is posted at ScholarlyCommons. https://repository.upenn.edu/oid_papers/80

For more information, please contact repository@pobox.upenn.edu. 


\title{
A Theoretical Framework for Goal-Based Choice and For Prescriptive Analysis
}

\begin{abstract}
This paper extends the familiar multi-stage framework for choice by explicitly describing the role that goals play at each stage. We first present a typology of goals, ranging from content to process and from immediate to long-term illustrating it in the context of two examples-purchasing a new car and earthquake retrofitting. We then delineate each stage of the choice process based on recent advances from the descriptive literature on the influence of the various goals. Finally, we draw the prescriptive implications as to how goals can inform what we know, or need to know, about the choice process.
\end{abstract}

\section{Keywords}

goals, choice process, prescription

Disciplines

Human Ecology | Organizational Behavior and Theory | Other Social and Behavioral Sciences | Other Sociology

\section{Author(s)}

Kurt A. Carlson, Chris Janiszewski, Ralph L. Keeney, David H. Krantz, Howard Kunreuther, Mary F. Luce, Joseph E. Russo, Stijn M. J. Osselaer, and Detlof V. Winterfeldt 


\section{A Theoretical Framework for Goal-Based Choice and for \\ Prescriptive Analysis}

Kurt A. Carlson

Duke University: The Fuqua School of Business

Chris Janiszewski

University of Florida, Warrington College of Business Administration

Ralph L. Keeney

Duke University: The Fuqua School of Business

David H. Krantz

Columbia University

Howard C. Kunreuther

Wharton School of the University of Pennsylvania

Mary Frances Luce

Duke University: The Fuqua School of Business

J. Edward Russo

Cornell University, Johnson Graduate School of Management

Stijn M. J. van Osselaer

RSM Erasmus University, Rotterdam

Detlof von Winterfeldt

University of Southern California

Contact:

Howard Kunreuther

The Wharton School, University of Pennsylvania

3730 Walnut Street, 500 Jon M. Huntsman Hall, Philadelphia, PA, 19104

Phone: 215-898-4589

Fax: 215-573-2130

Kunreuther@wharton.upenn.edu 


\begin{abstract}
This paper extends the familiar multi-stage framework for choice by explicitly describing the role that goals play at each stage. We first present a typology of goals, ranging from content to process and from immediate to long-term illustrating it in the context of two examples-- Purchasing a New Car and Earthquake Retrofitting. We then delineate each stage of the choice process based on recent advances from the descriptive literature on the influence of the various goals. Finally, we draw the prescriptive implications as to how goals can inform what we know, or need to know, about the choice process.
\end{abstract}

Key Words: goals, choice process, prescription. 
In contrast to most formal theories of consumer choice, we propose a framework based on goals. Decision makers attempt to satisfy numerous goals of different types (e.g., consumption, emotion, learning, process, social), given a variety of constraints (e.g., financial, cognitive, affective, temporal). In our view a goal-based theory of choice offers a useful bridge between prescriptive and descriptive consumer decision making.

The present article aims to contribute to such a goal-based theory of choice and to discuss its prescriptive implications. To make the discussion more concrete we focus on the following two examples:

- Purchasing a New Car A family is determining what type of car to purchase and needs to balance financial, social and other considerations in making the decision.

- Earthquake Retrofitting A family residing in the San Francisco Bay area is deciding whether to retrofit their pre-World War II home by bracing the walls (i.e., improving the structural integrity) and/or anchoring the structure to the foundation (i.e., improving the structural immobility).

\section{Toward a General Theory of Goal-Based Choice}

The emerging theory of goal-based choice builds on the recent converging work of several participants in this session (Bettman, Luce, \& Payne, 2007; Krantz \& Kunreuther, 2007; Russo et al. 2007; van Osselaer et al., 2005). We assume that preferences are constructed (Lichtenstein and Slovic, 2006) based on temporarily activated goals. We also assume that goal activation is a function of the cues that are available in the decision setting (Kruglanski et al., 2002).

In developing linkages between a descriptive model of choice and its prescriptive implications, we utilize a framework that comes out of the decision analysis literature. The framework contains 
five intertwined elements that correspond to the PrOACT model developed by Hammond, Keeney and Raiffa (1999). The five elements are:

1. Problem Recognition (Pr): Recognizing that there is a decision to be made and starting to define the problem,

2. Objectives (O) or Goals: Activating relevant goals (objectives),

3. Alternatives (A) or Plans: Searching for or designing alternatives or plans of action,

4. Consequences (C): Evaluating each alternative or plan against the activated goals, and

5. Tradeoffs (T) and Choice: Making tradeoffs by determining the specific amount of achievement on one goal that is equivalent in personal value to a specific level of achievement on another goal and using those tradeoffs as the basis for choosing a particular alternative/plan.

The next section presents a typology of goals and illustrates them in the context of the two examples introduced in the introduction. This typology is designed to enhance our understanding of the multiple influences on choice behavior and to provide a prescriptive decision aid. We then elaborate on each of the five steps of the above framework by reviewing important themes and recent advances from the descriptive literature and their implications for prescription. We also illustrate how prescription can inform what we know or need to know about the choice process.

\section{Goal Types}

We define a goal as a desired direction or state that guides behavior. In deciding what car to purchase, the family may have a financial goal of not spending more than $\$ 30,000$, a process goal of making the choice quickly, and an emotional goal of feeling good about the car buying experience. Regarding earthquake retrofitting, the California family may have a consumption goal of preventing serious damage to their house should an earthquake occur and an emotional goal of feeling secure even if an earthquake does not occur. 
Focusing on consumer choice, van Osselaer et al. (2005) distinguished among consumption, criterion (e.g. justification, learning, impression management) and process goals. Here we propose a more elaborate distinction. Table 1 illustrates seven goal categories for each of our two examples: Purchasing a New Car and Earthquake Retrofitting.

Goals associated with consumption, emotions, and learning are self-explanatory. The importance of the last depends (in part) on how well one knows the domain and/or their preferences (Hauser and Wernerfelt 1990) as well as on complex interactions between prior experiences of learning and the structure of the problem situation (Carlson and Pearo 2004; Dweck 1991). Process goals are those that are not associated with any particular alternative or plan but, instead, are confined to the process of choice (van Osselaer et al. 2005). Abstract life goals are general guides that influence many decisions. Keeney (1992) argues that people, who fail to consider such goals, risk not recognizing decision opportunities to make themselves better off. Social goals are related to affiliation so that in constructing this typology one must think about the interactions of a decision maker with other individuals or groups and the importance of social norms in the context of the choice that is being considered. Environmental goals can be very long-term and often require the cooperation of many players in order to be achieved.

\section{Insert Table 1 here.}

\section{Process Considerations and Prescriptive Implications}

In this section we consider the PrOACT model with respect to its descriptive features and prescriptive guidelines.

\subsection{Problem Recognition}

Descriptive Features. A decision must first be recognized and then structured in a preliminary way. Problem recognition is the least studied of the five phases (Russo and Carlson 2002), yet influences all that follows, including what goals are activated (Ranyard 1997, Schoemaker and 
Russo 2001). For instance, Rettinger \& Hastie (2001) showed that the same choice between a sure loss and a two-stage lottery is represented differently in the context of a casino gamble (a straightforward numerical calculation) and a traffic ticket (where moral principles are activated).

Not every action is preceded immediately by a goal-based decision process: some are consequences of a previously selected plan. For example, if one has previously decided to own an automobile, then inadequacy of one's current car triggers the search for a new one without recognizing any decision about whether or not to have a car. Similarly, most homeowners, especially those in areas of low seismic hazard, may never have chosen not to retrofit for earthquake protection. Thus, the alternative plans were never considered.

Prescriptive Guidelines. One important guideline is to take signals such as strong affect or dissent seriously. It is one thing to override "bad vibes" based on consideration of goals, possible actions, likely outcomes, and tradeoffs, and something quite different simply to ignore "bad vibes" by continuing with a previously selected plan. For example, one may be uncomfortable proceeding with a car purchase or with a contract to retrofit for earthquake because one distrusts or dislikes a salesperson or contractor. In the case of the car, one might override this dislike, reasoning that the goal of avoiding the salesperson is unimportant since later contact is not expected. A similar argument might be unconvincing in the case of retrofit, which entails a continuing interaction with the contractor. In either case, the recognition that there is a decision problem stems from the fact that an affect-laden decision system is already engaged.

In a group or organizational setting, "we have already decided that!" may be a poor reply, if the action resisted is one pursued on the basis of a previously adopted plan. One may need to modify that plan to insert a choice point, where a sub-plan could be selected in light of new circumstances or arguments. We speculate that many mistaken actions stem from failure to recognize a choice 
point, either because there is no affective or within-group signal resisting the action or because such resistance is simply ignored.

\subsection{Objectives: Activating Relevant Goals}

Descriptive Features. Many different goals, some fully conscious and others not, may be active during the choice process. A goal-based theory respects the potential influence of the full range of goals. Not only can features of choice alternatives activate consumption goals (Chartrand et al. forthcoming), but aspects of the choice process can activate processing goals (cf. Simonson 1989). A natural consequence is that goals should be able to influence behavior (e.g., search) that leads to the activation of other goals. As such, it is important to acknowledge that goals themselves are likely dynamically related during choice processes.

Although it may be difficult to measure activation levels of certain goals, knowledge of the choice context and the specific options available may be helpful in this regard. Carlson (2007) has found that by aiding goal recall with a detailed record of one's choice process, consumers can accurately recall changes in the activation of their goals during a choice process. Being in the social environment of a restaurant's bar may activate the goal of social drinking while receiving a dessert menu at the end of the meal may activate a health or diet goal. It is also important to recognize that goals themselves are interrelated. For example, effort and justification are both important process goals related to decision making (e.g., Bettman, Luce and Payne 1998), and at times, the achievement of one may hinder the pursuit of the other.

Behavioral decision research has a long tradition of demonstrating that contextual factors influence choice. One of the classic examples is the activation of loss aversion goals. While gains are often expected and hence do not generate much affective behavior, corresponding losses tend to be unexpected and thereby evoke strong negative emotions. In the case of the retrofit example, 
severe damage to one's property from an earthquake may generate a set of negative emotions such as fear and worry, thus stimulating interest in allocating funds for reducing future losses.

One interesting source of goal activation is the nature of the default option. Johnson and Goldstein (2003) argue that organ donation is positively influenced by “opt-out” plans suggesting donation as the default. They argue this occurs not only because the calculus of loss aversion favors sticking with the status quo, but also because choosing the default better satisfies the process goal of minimizing effort. Fischbach, Friedman and Kruglanski (2003) find that temptations (attractive vice options such as unhealthy foods) automatically activate overriding goals (e.g., health), and that these goals can in turn inhibit temptations. Even if options are not exercised they may alter goals or introduce others that are considered when making choices. Kahn and Dhar (2007) find that the option of making a virtuous choice on a later trial encourages current choice of vices, presumably because the decision makers expect to redeem themselves later by consuming virtues.

Process goals, including those related to emotional or social factors, can be generated by context or specific alternatives as well. For instance, Luce, Payne and Bettman (1999) find that both a loss frame and a choice response mode generate more tradeoff-avoidance. The apparent cause is the process goal of minimizing the negative emotion associated with responsibility for difficult tradeoffs. Likewise, the mere presence of a dominated option (i.e., one alternative that is worse than another alternative in every respect), both gives decision makers a means to satisfy the reasons goal (the dominance relationship justifies choosing the dominating alternative) and results in the increased activation of this goal (Carlson 2007).

Recent research has begun to investigate inhibition as well as activation of goals. Brendl, Markman and Messner (2003) find that activating a need makes options unrelated to that need less attractive and that this effect operates outside of awareness. On the one hand, a vigorous gym workout may increase the propensity for a high-fat meal, as exercising licenses the vice (see also 
Fishbach, Dhar and Zhang 2006). On the other hand, the same work-out may decrease the tendency to seek the high-fat meal, as the exercise underscores commitment to healthy living. In the latter case, satisfying a goal can become reinforcing (see also Shah, Friedman and Kruglanski 2002). Laran, Janiszewski and Cunha (2007) find that initial goal-directed behavior increases commitment to the goal unless that goal is achieved or otherwise released.

The available alternatives themselves can provide a powerful and ubiquitous route to the activation of social goals. In the car example, seeing a very attractive vehicle in a showroom might easily activate goals that were previously weak or absent, such as impressing one's neighbors or achieving social success. In a negotiation, the social goals of cooperation and of increasing the total "pie" may drive the search for novel alternatives that offer win-win possibilities for both sides. For example, homeowners are often reluctant to invest in cost-effective mitigation measures because they perceive the cost to be too high relative to expected benefits over a short time horizon, maybe 2 or 3 years. To alter this cost-benefit imbalance, banks could offer home improvement loans tied to the mortgage, and insurers could reduce their premiums to reflect the lower risk. Then the total cost of insurance and the loan would be lower for the homeowner who undertook the mitigation measure than for one who maintained the status quo. This would be a win-win-win situation for the insurer, bank, and consumer (Kunreuther 2006).

Prescriptive Guidelines. The challenges for prescription are recognizing the full set of relevant goals and determining their importance. Regarding recognition, a checklist of goal types is one useful tool to help avoid overlooking goals (Bond, Carlson, and Keeney 2007). Reading an article on "how to buy an automobile" is likely to prompt goals that might not otherwise be considered, such as the need to tow something or rear doors large enough to accommodate aged relatives. A checklist may be particularly useful in participatory decision-making, where different individuals have different goals, some shared and others not. Other goal generation techniques take the 
available alternatives as their starting point. These include probing for why specific alternatives are good or bad, using consequences to reveal goals, and continuing to ask why something is important (Hammond, Keeney and Raiffa, 1999).

Reframing the problem may generate goals that would otherwise not be raised to consciousness. Homeowners who view the decision on retrofitting their property as providing peace of mind may be more likely to decide to undertake this investment than if they considered the goal of minimizing cost. Pricing automobile insurance at $\$ 100$ per month sounds more attractive than $\$ 1200$ per year and may influence how much one is willing to pay for a car. Similarly a lifetime expenditure of $\$ 50,000$ for automobile liability insurance would be better framed as $\$ 1000$ per year for 50 years. In the yearly frame, it becomes part of the annual cost of owning and operating a car, rather than a huge loss. An annual frame recognizes that one stops paying for insurance when one no longer owns a car. Other techniques, like systematically exploring multiple selves, social roles, temporal frames, views of others, influences on other decisions, and reference points, might help generate a wide range of goals in the appropriate decision situation (e.g., Keeney 1992).

One of the challenges in "surfacing” goals is forcing decision makers to reveal considerations that that they would prefer to keep hidden, such as those that are self-serving. In a car purchase, a husband's desire to experience the excitement of speed may not be openly discussed when making the family car purchase. In a retrofit decision, a spouse's displeasure with his job or mate, and the accompanying desire to leave the area, may not be openly acknowledged when discussing the merits of retrofitting. Hidden goals might be brought out by making them respectable, such as, "How long do you imagine living in this house?"

Emotions often signal important underlying goals but might also cause the overweighting of certain outcomes (e.g., Rottenstreich and Hsee 2001). Prescriptions might include methods to challenge the importance of emotional goals, such as drawing attention to the likelihood of risk or 
asking the decision maker to consider her situation from the perspective of a dispassionate observer or a credible professional. Such techniques may, for instance, encourage a more deliberative mindset whereby the decision maker is less likely to choose based on events that are vivid and feared, yet extremely unlikely.

A second prescriptive challenge is achieving stability of recognized goals over time. We specifically mean a match between the relative importance of goals when the decision is made and when the consequences are experienced. One does not want a consumer who has followed prescriptive advice to say later, “What was I thinking when I bought that car?” One important tactic might be context matching whereby the environmental factors at play during the experience of consequences match those during the making of the decision (Payne, Bettman \& Schkade 1999). For instance, if an automobile is going to be driven primarily as a "family car," test drives including children may better predict ultimate satisfaction. Some goals may be particularly susceptible to variation over contexts, especially between the decision and consumption contexts. In such cases it may be useful to measure a goal's activation at multiple times to assess its instability and to estimate a more stable level of activation. Recent work by Laran, Janiszewski and Cunha (2007) suggests that it might be possible to allow goals to stabilize through "release from goal pursuit". Temporary goals often inhibit the activation of more chronic goals. Once temporary goals are met, long term chronic goals can be more accurately assessed.

\subsection{Alternatives: Searching for or Designing Plans}

Descriptive Features. In laboratory experiments, plans of action (or choice options) are constructed by an experimenter in order to examine specific decision processes. Outside the laboratory, however, only a few alternative plans may be considered. Field studies suggest that decision makers tend to adopt at most one measure to reduce risk, even though different individuals choose different measures and often the best plans are a complex mixtures of these simpler ones 
(Weber, 1997). Most plans and alternatives considered are minor modifications of ones retrieved from memory. "How did we do it last time?" is an oft-heard refrain from those who have to decide what action to take. The retrieval of "similar cases" from memory is a focus on the study of expertise (e.g., Seifert et al. 2002). Creativity, or "thinking outside the box,” is recognized when the set of options offered or retrieved initially from memory is rejected and a rather different option is proposed.

When there are several alternatives or plans, the decision maker may impose structure on the set by examining their differences with respect to particular goals. For example, structure may be imposed by activating the goal of attribute-based processing. Such processing may then activate the goal of minimizing cognitive effort (i.e., simplifying choice), which, in turn, may encourage noncompensatory decision processes.

Prescriptive Guidelines. Much of the art of decision aiding lies in methods used to generate a broad set of possible alternatives for consideration by the individual or group. Maybe most important, one needs to consider the creation of alternatives to be a task worthy of time and effort. For each of the objectives or goals, ask what would be a highly satisfactory alternative if this were the only objective. This stretches decision makers' thinking and provides component aspects of what might be a surprisingly good actual alternative.

Techniques for generating alternatives include:

- challenging the assumptions that may exclude good options

- using others to help generate alternative courses of action

- changing the framing of the decision, for instance to that of a customer or client, and

- eliciting and comparing mental representations among decision makers.

Studies of memory suggest why the process of generating an adequate set of action plans is so important to the prescriptive side of decision making. Memory-based failure to generate sufficient options (Russo and Kolzow 1994), and the negative reaction to too many options (Iyengar \& Lepper 
2000), pose competing challenges to prescriptive analyses. Prescriptive techniques include using goals to generate options. Decision makers could be urged to focus on alternatives to the status quo or to create options by temporarily ignoring assumed constraints. For instance, options could be elicited that serve only one goal and then used to create new ones that can satisfy multiple goals by creatively combining aspects of "single-goal ideal options.” New parents purchasing an automobile may focus solely on safety, but when reminded of their commitment to the environment, they may strive to find options that meet both goals.

\subsection{Consequences: Evaluating the Alternatives in Light of the Goals that are Active}

Descriptive Features. Both failure of memory and lack of imagination may undermine full anticipation of the impact of a particular action on one's goals. To return to the example of purchasing a new car, consumers may not consider the likelihood of buying a boat that the car must tow or that illness may require an aged parent to be transported. In some cases, not only likelihood, but the degree of satisfaction of each goal must be evaluated. For example, in considering earthquake retrofitting of a house, one considers the cost against how much it will reduce the likely damage, anxiety, etc. In many observed decision processes, likelihood is not considered, even when probabilities are stated (Kunreuther 2001).

Prescriptive Guidelines. Establishing the link between the goals and their relevant consequence measures is in itself an important prescriptive task (Keeney and Winterfeldt 2007). In the car example, one goal might be "performance” measured as the time it takes to accelerate the car from 0 to 60 miles per hour; another goal might be fuel economy measured in miles per gallon. Having established consequence measures, the next task is to estimate how well the alternatives do on these measures, something that can require experts’ judgments.

A special problem occurs when the alternatives involve risks. For example, when choosing between earthquake retrofitting alternatives, one has to consider the amounts that the goals are 
attained both if an earthquake occurs (unlikely, but possibly disastrous) and if it does not. In prescriptive analysis, risks are modeled as probability distributions over consequences. This modeling task is, in itself, a complete field of prescriptive analysis, usually referred to as "risk analysis.” Such modeling is not always available when needed, but one can at least remind decision makers to think about the relevance of uncertain events, for each option under consideration.

\subsection{Tradeoffs and Choice.}

Descriptive Features. The fundamental task of this last phase of decision making is to make tradeoffs among attainment of the various, competing goals so as to identify a preferred alternative or plan. One aspect of how such tradeoffs are accomplished is whether the process is more deliberative or more intuitive and less conscious. The latter mode of processing often facilitates the influence of more affective goals on the choice.

The role of emotional process goals in decision tradeoffs is being increasingly appreciated (Luce, 1998; Luce, Bettman and Payne, 2001). This research finds that decision makers prefer to avoid some emotion-eliciting tradeoffs, even in the overall context of effortful deliberation. Some decision makers might use a more automatic affective system to integrate the activation of multiple goals and assign decision weights to these goals. Integration by automatic affective reaction might reflect a higher activation for some goals (e.g., avoiding dread risks) as pointed out by Slovic et al. (2002) and might also lead to suboptimal weighting of probabilities (Rottenstreich \& Hsee 2001).

Other decision makers might be more deliberative by trying to find a common subjective scale for evaluating different goals or focusing on one goal or attribute at a time and comparing plans with respect to it. Within these more deliberative systems, contextual and process-goal considerations can alter the tradeoff process. Dhar and Simonson (1999) find that the tradeoff between a goal (e.g., tasty food) and resource (e.g., money) encourages highlighting of the goal, 
while tradeoffs between competing goals (e.g., tasty food, healthy food) encourage balancing. In the latter case the goals are traded off, such as when a low-fat dinner is followed by a decadent dessert.

Some goals are important enough to be converted into constraints. An obvious example is the goal of meeting one’s budget and hence not looking at new cars that cost more than $\$ 30,000$. Even such a constraint may include a probability or decision weight. For example, one may consider only plans that have "near certainty" or a specified high probability of not exceeding the nominal budget by more than $5 \%$. In purchasing a new car one may focus on the sticker price, recognizing that when purchasing all the extra equipment there is some chance of exceeding the $\$ 30,000$ budget constraint. Goals with implications for moral or otherwise protected values tend to be treated as constraints (Baron and Spranca 1997), at least in part due to the negative emotion associated with trading off these goals (Luce, Bettman and Payne 2001).

Much of what falls into this fifth phase of the choice process evolves from studies of anomalies that cannot be explained by formal models of choice such as utility theory and prospect theory. Subjective expected multi-attribute utility theory (SEMAUT) and cumulative prospect theory (CPT) utilize a strategy/event structure. The structure uses a common value function and a numerical measure of likelihood of each event to value options across all goals.

Krantz and Kunreuther (2007) have developed a formal model of choice that is goal-based. Individuals compare alternatives (always termed plans) by determining how well each of them satisfies the set of goals, each goal having a given value and a decision weight that reflects how likely the goal will be satisfied by the given option. The alternative that is selected depends on the decision rule used by the individual, one of which could be an additive/multiplicative formula such as the one used to calculate SEMAUT. The plan selected is generally the one with high decision weights associated with important goals. 
One can also construct models that evaluate alternatives in terms of goal activation and decision weights. Tradeoffs are often represented by weighted-sum decision rules, which usually yield good approximations descriptively (Yntema \& Torgerson, 1961; but see Dawes 1979, for an argument that including the relevant goals matters more than the precise weights). Such rules can easily be incorporated into process models (e.g., Janiszewski \& van Osselaer 2005). Process models allow for the current level of goal activation, and the history of means effectiveness for a given goal, to jointly determine the attractiveness of the available means.

Prescriptive Guidelines. The use of constraints as a tradeoff avoidance mechanism raises a prescriptive question as to when it is appropriate to simplify the choice process by converting important goals into constraints. On the one hand, a constraint may be converted into a goal that is then included in the tradeoff process. One procedure is to have individuals initially formulate and evaluate alternatives that do not meet all of the initial constraints. On the other hand, converting very important goals into constraints can be a useful step in simplifying the consideration of tradeoffs among the remaining goals. The risk is that if the constraints are too binding, they can cause one to neglect the consideration of otherwise utility-maximizing options.

A traditional approach to the tradeoff phase is a value model that evaluates how well each alternative performs on each of the goals, and can then integrate these goal evaluations. Prescriptively, the foundation for such a model is a set of fundamental goals usually referred to in such models as objectives. The main technical issue is then to get useful tradeoffs among these desirable objectives. This process requires a balance between what is doable and what is worthwhile to do. Keeney and von Winterfeldt (2007) discuss the practical issues of this process.

\section{Conclusions and Future Research}

The interdependencies between good descriptive decision research and good prescriptive decision analysis are clear. Judgments and human processes are required for every input to a 
prescriptive decision analysis (e.g., defining the decision problem, specifying objectives, creating alternatives, constructing a value model). Decision analysts can learn from descriptive decision research the shortcomings of such information, why these occur, and what to do about them.

Descriptive decision research is intended to be relevant to real decisions by understanding how choices are made. Prescriptive research by decision analysts is designed to improve this process and the selection of a final choice. Unfortunately, many decision researchers and decision analysts pursue their work as if they are not knowledgeable about the others body of work or lack understanding of its relevance to their own interests. This circumstance suggests numerous opportunities for new important research in both areas. 


\section{REFERENCES}

Baron, Jon and Mark Spranca. (1997). "Protected values,” Organizational Behavior and Human Decision Processes 70, No. 1, April, pp. 1-16,

Bettman, James R., Mary Frances Luce, and John W. Payne. (2007). “Consumer decision making: A goals choice approach”, chapter to appear in Haugtvedt, C. P. Herr, P., \& Kardes, F. (Eds.). Handbook of Consumer Psychology. Hillsdale NJ: Erlbaum.

Bettman, James R., Mary Frances Luce, and John W. Payne. (1998). “Constructive Consumer Choice Processes,” Journal of Consumer Research, 25 (December), pp. 187-217.

Bond, Samuel, Kurt A. Carlson, and Ralph Keeney. (2007). “Generating Objectives: Can Decision Makers Articulate What They Want?” Management Science, in press.

Brendl, C. Miguel, Arthur B. Markman, and Claude Messner. (2003). “The Devaluation Effect: Activating a Need Devalues Unrelated Objects” Journal of Consumer Research 29, pp. 463-473.

Carlson, Kurt A. (2007). “Consumers’ Decision Process Goals”, working paper. Duke University.

Carlson, Kurt A. and Lisa K. Pearo. (2004). "Limiting predecisional distortion by prior valuation of attribute components”, Organizational Behavior and Human Decision Processes, 94 (1), pp. 48-59.

Chartrand, Tanya J., et al. (2007b). "Nonconscious Goals and Consumer Choice”, Journal of Consumer Research, forthcoming.

Dawes, Robyn M. (1979). “The Robust Beauty of Improper Linear Models,” American Psychologist, 34 (7), pp. 571-582.

Dhar, Ravi and Itamar Simonson. (1999). "Making Complementary Choices in Consumption Episodes: Highlighting versus Balancing”, Journal of Marketing Research, 36, (1), pp. 29-44.

Dweck, Carol S. (1991). “Self-theories and goals: Their role in motivation, personality, and development,” In Dienstbier, Richard A (Ed). Nebraska Symposium on Motivation, 1990: Perspectives on motivation. (pp. 199-235). Lincoln, NE, US: University of Nebraska Press.

Fishbach, Ayelet, Ravi Dhar and Ying Zhang. (2006). "Subgoals as Substitutes or Complements: The Role of Goal Accessibility,” Journal of Personality and Social Psychology, 91 (August) pp. 232-242.

Fishbach Ayelet, Ron S. Friedman, and Arie W. Kruglanski. (2003). "Leading us not unto temptation: momentary allurements elicit overriding goal activation”, Journal of Personality and Social Psychology, 84(2), 296-309

Hammond, John. S., Ralph L. Keeney, and Howard Raiffa. (1999). Smart Choices: A Practical Guide to Making Better Decisions. Boston: Harvard Business School Press 
Hauser, John R. and Birger Wernerfelt. (1990). “An Evaluation Cost Model of Consideration Sets”, Journal of Consumer Research, 16(4), 393-408.

Iyengar, Sheena S., and Mark R. Lepper. (2000). "When Choice is Demotivating: Can One Desire Too Much of a Good Thing?” Journal of Personality and Social Psychology, 79, 995-1006. (2000)

Janiszewski, Chris and Stijn M. J. van Osselaer. (2005). "Behavior Activation is Not Enough," Journal of Consumer Psychology, 15 (3), 218-24.

Johnson, Eric J. and Daniel Goldstein. (2003). “Do Defaults Save Lives,” Science 1. 302. no. 5649, pp. $1338-1339$

Kahn, Uzma and Ravi Dhar. (2007). "Where There Is a Way, Is There a Will? The Effect of Future Choices on Self-Control” (with U. Khan), Journal of Experimental Psychology: General, 2007

Keeney, Ralph L. (1992). Value-Focused Thinking, Harvard University Press: Cambridge MA.

Keeney, Ralph L. and Detlof von Winterfeldt. (2007). "Practical Value Models" in Edwards, W. Miles, R.F. Jr., and von Winterfeldt, D, Ed Advances in Decision Analysis. New York: Cambridge.

Krantz, David H. and Howard C. Kunreuther. (2007). “Goals and plans in decision making”, Judgment and Decision Making, Vol. 2, No. 3, June 2007, pp. 137-168.

Kruglanski, Arie, et al. (2002), "A Theory of Goal Systems," in Advances in Experimental Social Psychology, Mark P. Zanna, Ed. San Diego, CA: Academic Press.

Kunreuther, Howard. (2001). "Protective Decisions: Fear or Prudence,” In Steven J. Hoch, Howard C. Kunreuther and Robert E. Gunther (eds.). Wharton on Making Decisions. New York: Wiley

Kunreuther, Howard. (2006), “Disaster Mitigation and Insurance: Learning from Katrina”, The Annals of the American Academy of Political and Social Science, 604: 208-227.

Laran Juliano, Chris Janiszewski, and Marcus Cunha Jr. (2007). “Content-Dependent Effects of Goal Primes”, working paper, University of Florida.

Lichtenstein, Sarah. and Paul Slovic. (2006). The Construction of Preference. Cambridge: Cambridge University Press. (eds.)

Luce, Mary Frances. (1998). "Choosing to avoid: Coping with negatively emotion-laden consumer decisions”, Journal of Consumer Research, 24, 409-433.

Luce, Mary Frances, John W. Payne, and James R. Bettman. (1999). "Emotional trade-off difficulty and choice”. Journal of Marketing Research, 36, 143-159.

Luce, Mary Frances, James R. Bettman, and John W. Payne. (2001). “Emotional decisions: Tradeoff difficulty and coping in consumer choice." Monographs of the Journal of Consumer 
Research, 1. Chicago: University of Chicago Press.

Payne, John W., James R. Bettman, and David A. Schkade. (1999). ’Measuring constructed preferences: Towards a building code”, Journal of Risk and Uncertainty, 19, 243-270.

Ranyard, Rob (1007). Decision-making: Cognitive Models and Explanations. London and New York: Routledge.

Rettinger, David A. and Reid Hastie. (2001). "Content effects on decision making,” Organizational Behavior and Human Decision Processes, 85 (2), pp. 336-359.

Rottenstreich, Yuval, and Christopher K. Hsee. (2001). ”Money, kisses, and electric shocks: On the affective psychology of risk.” Psychological Science, 12, 185-190.

Russo, J. Edward and Kurt A. Carlson. (2002). “Individual Decision-making” In Barton Weitz and Robin Wensley (eds.) Handbook of Marketing, Sage Publications, Chapter 15, pp. 371-408

Russo, J. Edward, Kurt A. Carlson, Meloy, M. G., \& Kevyn Yong. (2007). “The Goal of Consistency as a Cause of Information Distortion”, Working Paper, Cornell University, August.

Russo, J. Edward and Karen J. Kolzow. (1994). "Where Is the Fault in Fault Trees?” Journal of Experimental Psychology: Human Perception and Performance, 20(1), 17-32.

Schoemaker, Paul J.H. and J. Edward Russo. (2001). “Managing frames to make better decisions”. In Steven J. Hoch, Howard C. Kunreuther and Robert E. Gunther (eds.), Wharton on Making Decisions, New York: John Wiley and Sons, Inc., pp. 131-155.

Schwartz, Barry. (2004). The paradox of choice: Why more is less. New York: Ecco.

Seifert, Colleen M., et al. (2002). “Case-Based Learning: Predictive Features in Indexing.” In T. A. Polk and C. M. Seifert (Eds.), Cognitive Modeling, pp. 987-1007. Cambridge MA: MIT Press.

Shah, James Y., Ron Friedman, Arie W. Kruglanski. (2002). "Forgetting All Else: On the Antecedents and Consequences of Goal Shielding," Journal of Personality and Social Psychology, 83 (December), pp. 1261-1280.

Shah, James Y. and Arie W. Kruglanski. (2003). "When opportunity knocks: Bottom-up priming of goals by means and its effects on self-regulation," Journal of Personality and Social Psychology, 84 (6), 1109-22.

Simonson, Itamar (1989). “Choice Based on Reasons”, Journal of Consumer Research, 16, pp. 158-164.

Slovic, Paul, et al. (2002). "The affect heuristic.” In T. Gilovich, D. Griffin, and D. Kahneman (eds.), Heuristics and biases: The psychology of intuitive judgment (pp. 397-420). New York: Cambridge University Press. 
van Osselaer, Stijn M. J., et al. (2005), "Choice Based on Goals," Marketing Letters, 16 (3-4), 33546.

Weber, Elke U. (1997). “The utility of measuring and modeling perceived risk”. In: A.A.J. Marley, (ed.), Choice, Decision, and Measurement: Essays in Honor of R. Duncan Luce, Lawrence Erlbaum Associates, Mahwah (1997), pp. 45-57.

Wilson, Timothy D., and Jonathan W. Schooler. (1991). "Thinking too much: Introspection can reduce the quality of preferences and decisions”. Journal of Personality and Social Psychology, 60, 181-192.

Yntema, Douwe B. and Warren S. Torgerson. (1961). "Man-computer cooperation in decisions requiring common sense”, IRE Transactions of the Professional Group on Human Factors in Electronics, 2, 20-26. 
Table 1: Multiple goals for two types of decisions

\begin{tabular}{|c|c|c|}
\hline \multicolumn{3}{|l|}{ Decision Example } \\
\hline Goal Type* & Purchasing a New Car & Earthquake Retrofit \\
\hline Consumption & $\begin{array}{l}\text { Comfortable ride } \\
\text { Power and handling } \\
\text { Freedom from breakdown } \\
\text { Avoid undue expense } \\
\text { Have fun driving }\end{array}$ & $\begin{array}{l}\text { Reduced damage (if quake occurs) } \\
\text { Avoid undue expense }\end{array}$ \\
\hline Emotion & $\begin{array}{l}\text { Relief from old-car hassles } \\
\text { Absence of regret }\end{array}$ & $\begin{array}{l}\text { Reduced anxiety about quakes } \\
\text { Absence of regret }\end{array}$ \\
\hline Learning & About cars and prices & $\begin{array}{l}\text { About seismic waves, soils, building } \\
\text { structures }\end{array}$ \\
\hline Process & $\begin{array}{l}\text { Minimize cognitive effort } \\
\text { Consider all aspects } \\
\text { Cognitive consistency }\end{array}$ & $\begin{array}{l}\text { Minimize cognitive effort } \\
\text { Consider all aspects } \\
\text { Cognitive consistency }\end{array}$ \\
\hline Abstract/Life & $\begin{array}{l}\text { Do right } \\
\text { Enjoy life }\end{array}$ & $\begin{array}{l}\text { Be prudent } \\
\text { Protect self and family }\end{array}$ \\
\hline Social & $\begin{array}{l}\text { Feel sexier (prompted by TV } \\
\text { ads) } \\
\text { Justify to others } \\
\text { Conform to expectations } \\
\text { Passenger safety/comfort } \\
\text { Partner's fun driving } \\
\text { Car sharing } \\
\text { Other drivers' needs } \\
\text { Avoid partner conflict } \\
\text { Avoid/support bus system } \\
\end{array}$ & $\begin{array}{l}\text { Conform to neighbor’s action } \\
\text { Justify to others } \\
\text { Protect family from injury or death } \\
\text { Conform to law and custom } \\
\text { Set or support norms } \\
\text { Save toward other social goals }\end{array}$ \\
\hline Environmental & Minimize $\mathrm{CO}_{2}$ & Preserve neighborhood (if quake) \\
\hline
\end{tabular}

